\title{
Manufacturing and compatibilization of PLA/PBAT binary blends by cottonseed oil-based derivatives
}

\author{
A. Carbonell-Verdu ${ }^{1}$, J. M. Ferri ${ }^{1}$, F. Dominici $^{2}$, T. Boronat ${ }^{1 *}$, L. Sanchez-Nacher ${ }^{1}$, R. Balart ${ }^{1}$, \\ L. Torre ${ }^{2}$ \\ ${ }^{1}$ Technological Institute of Materials (ITM), Universitat Politècnica de València (UPV), Plaza Ferrándiz y Carbonell 1, \\ 03801 Alcoy, Alicante, Spain \\ ${ }^{2}$ Dipartimento di Ingegneria Civile e Ambientale, Università di Perugia, Strada di Pentima, 4, 05100, Terni, Italy
}

Received 5 February 2018; accepted in revised form 1 May 2018

\begin{abstract}
This research work aims at the compatibilization of poly(lactic acid)/poly(butylene adipate-co-terephthalate), PLA/PBAT binary blends by using cottonseed oil derivatives, i.e. epoxidized (ECSO) and maleinized (MCSO) cottonseed oil. The potential of these vegetable oil-based compatibilizers are compared versus the effects of a conventional styreneacrylic oligomer. The base PLA/PBAT binary blend composition was $80 \mathrm{wt} \%$ PLA/20 wt $\%$ PBAT and the amount of compatibilizer was set to 1 and $7.5 \mathrm{wt} \%$. The effects of the different compatibilizers were evaluated on PLA/PBAT films in terms of mechanical and thermal properties as well as blend's morphology by field emission scanning electron microscopy (FESEM). Complementary, biodisintegration tests in controlled compost soil and surface properties were evaluated to assess the effects of the compatibilizers. Addition of $1 \mathrm{wt} \%$ ECSO and MCSO led to a remarkable increase in the elongation at break up to values over $100 \%$ with regard to neat PLA. Despite this, maximum elongation at break was obtained for the compatibilized PLA/PBAT blend with $7.5 \mathrm{wt} \%$ MCSO, reaching values of about $321.2 \%$ respect neat PLA keeping mechanical resistant properties, such as Young's modulus and tensile strength, at high levels. Therefore, vegetable oil-derived compatibilizers stand out as environmentally friendly additives for PLA/PBAT binary blends with improved properties.
\end{abstract}

Keywords: biopolymers, biocomposites, poly(lactic acid), cotton seed oil, maleinization

\section{Introduction}

Poly(lactic acid), PLA is currently considered as one of the most promising polymers from renewable resources, due to an excellent balance between mechanical properties and a competitive price day by day [1]. Nevertheless, it is intrinsically quite brittle, its chemical barrier behavior is not optimum compared to other widely used polymers, its thermal stability is also restricted and its resistance to external agents (UV radiation, moisture, etc.) are issues to overcome. For this reason, industrial PLA and other polymer formulations usually contain several additives with different purposes thus widening its use in sectors such as agriculture [2], packaging [3, 4], medical devices [5], 3D printing, textile fibers [6]. With the aim of a sustainable development and a low environmental impact, biobased additives are been searched, i.e. antioxidants, plasticizers, fillers, etc. [7-10]. With the increasing development of nanotechnology, many research works have been focused of using nanostructures to improve the properties of PLA-based materials [11-13] and interactions.

Typical PLA materials are characterized by low toughness and this is one of the main drawbacks in a massive use of this biopolyester. A broad range of approaches has been observed in the last decade to minimize this effect $\mathrm{Xu}$ et al. [14] reported a new 
injection molding technology (oscillating shear) to improve all properties of PLA, including its toughness. One of the easiest methods to overcome the intrinsic brittleness of PLA is by physical blends with ductile polymers [15]. A wide variety of binary and ternary blends with PLA have been proposed as a technical solution to improve toughness. Among others, it is worthy to note some interesting PLAbased blends with poly( $\varepsilon$-caprolactone)(PCL) [16], thermoplastic starch (TPS) [17], poly(butylene succinate) (PBS) [18], poly(butylene succinate-co-adipate) (PBSA) [19], poly (glycolic acid) (PGA) [20], poly(hydroxybutyrate) (PHB) [21], poly(hydroxybutyrate-co-valerate) (PHBV) [22], poly(butylene adipate-co-terephthalate) (PBAT) [23], etc. Ternary blends allow obtaining tailored properties in PLAbased blends [24, 25]. Despite some increase in mechanical ductile properties are achieved with these blends, most of PLA-based blends show partial or total immiscibility, being this an important drawback to obtain synergistic effects. To improve compatibility between immiscible of partially miscible polymers, different approaches have been proposed. Reactive extrusion stands out as a cost effective alternative to copolymerization [26]. Reactive extrusion with PLA considers chemical reactions with some additives such as triphenyl phosphite, adimides (e.g. Bioadimide $^{\circledR}$ ), epoxy-based styrene-acrylic oligomers $\left(\right.$ e.g. Joncryl $\left.{ }^{\circledR}\right)$, glycidyl copolymers [27], etc. with the hydroxyl terminal groups present in PLA and other biobased polyesters. This allows chain extension and/or branching with a positive effect on compatibilization of both polymers in the blend with a subsequent improvement in toughness. Ojijo et al. [28] developed PLA/PBSA blends with 2\% triphenyl phosphite (TPP). They reported an increase in elongation at break of $37 \%$ and the energy absorption changed from $6.76 \mathrm{~kJ} \cdot \mathrm{m}^{-2}$ (neat PLA) up to $16.4 \mathrm{~kJ} \cdot \mathrm{m}^{-2}$ for the PLA blend with $10 \%$ PBSA and $2 \%$ TPP. Over $2 \%$ TPP, over-crosslinking occurs and properties are not improved. Al-Itry et al. [29] studied the effect of Joncryl ADR-4368 (an epoxidized styrene-acrylic oligomer) on PLA/PBAT blends. In fact, they reported a percentage increase in the elongation at break of $900 \%$ with regard to neat PLA. In addition, the other mechanical properties were not affected to a great extent, since the effect of this oligomer is not only chain extension, but also branching and/or crosslinking as reported by Torres-Giner et al. [30].
Similar results have been reported with reactive extrusion by generating free radicals during the extrusion process, which can be achieved by using organic peroxides. This leads to a combination of chain extension, branching and crosslinking. Bureepukdee et al. [31] compared the compatibilizing effect of di(tert-butylperoxy isopropyl) benzene (DTBP) and 2, 5-dimethyl-2, 5-(t-butylperoxy) hexane (DTBH). They reported a continuous phase by using $0.1 \mathrm{phr}$ DTBP on a binary PLA blend with $40 \%$ PBSA with a remarkable increase in ductility.

With the aim of obtaining high environmentally friendly PLA formulations, the use of vegetable-oil (VO)-derived additives is increasing as vegetable oils can be chemically modified to tailor some particular functionalities which can react with PLA and other biopolyesters. Currently, epoxidized vegetable oils (EVOs) are widely used in the new generation of environmentally friendly plasticized PVC formulations [32, 33] and thermosetting resins [34]. Their use in the packaging industry is attracting due to low migration rates towards the food [35]. A new generation of biobased poly(urethanes) has been developed by using vegetable oil-derived polyols [36]. Modified vegetable oils could potentially act as compatibilizers in binary and ternary blends. Some vegetable oils (those with unsaturated fatty acids such as oleic, linoleic, linolenic, etc.) can be subjected to a wide variety of chemical modifications such as epoxidation, acrylation, hydroxylation, maleinization, etc. among others. With these processes, oxirane rings, acrylic groups, hydroxyl groups and maleic anhydride, and other functional groups can be added to the vegetable oil structure thus increasing their reactivity towards terminal hydroxyl groups in PLA and other biopolyesters.

In previous works, cotton seed oil (CSO) was chemically modified by conventional epoxidation process [35] to obtain epoxidized cotton seed oil (ECSO). Moreover, CSO was subjected to a maleinization process with maleic anhydride [37] to give maleinized cotton seed oil (MCSO). Both CSO-derivatives showed a clear plasticization effect on PLA. Specifically, the addition of $10 \mathrm{wt} \%$ ECSO led to a noticeable increase in elongation at break up to values of $110 \%$ of PLA, characterized by an elongation at break close to $9 \%$. Similar findings were obtained with MCSO. Ferri and coworkers [38, 39] studied the effect of maleinized linseed oil (MLO) as compatibilizer in PLA/TPS blends. Two different phenomena 
were attributed to MLO: on one hand, a clear plasticization effect was observed but on the other hand, MLO also acted as a compatibilizer with a remarkable improvement on miscibility on such binary blends. Furthermore, MLO contributed to improve the processing of PLA/TPS blends.

The main aim of this research work is to assess the potential of cottonseed oil derivatives, i.e. epoxidized cottonseed oil (ECSO) and maleinized cottonseed oil (MCSO) as compatibilizers in PLA/PBAT binary blends. The effect of these two vegetable oilderived compatibilizers is compared with a conventional epoxy styrene-acrylic oligomer in terms of mechanical properties, thermal stability, thermomechanical properties and blend's morphology. The novelty of this work is the assessment of cottonseed oil as potential base material for blend compatibilization with comparable features to other commercially available modified-vegetable oils. This widens the use of cottonseed wastes in industrial applications and contributes to high biobased content materials.

\section{Experimental}

\subsection{Materials}

The PLA grade used was Ingeo ${ }^{\mathrm{TM}}$ Biopolymer 2003 D supplied by NatureWorks LLC (Minnetonka, USA) in pellet form with a density of $1.24 \mathrm{~g} \cdot \mathrm{cm}^{-3}$ and a melt flow index of $6 \mathrm{~g} /(10 \mathrm{~min})$ measured at $210^{\circ} \mathrm{C}$. A PBAT commercial grade Biocosafe ${ }^{\mathrm{TM}} 2003 \mathrm{~F}$ was supplied by Xinfu Pharmaceutical Co. Ltd. (Zhejiang, China) and it is characterized by a density of $1.25 \mathrm{~g} \cdot \mathrm{cm}^{-3}$ and a melt flow index $<6 \mathrm{~g} /(10 \mathrm{~min})$ at $190^{\circ} \mathrm{C}$. PBAT has been selected because of its flexibility (an average tensile strength of $14 \mathrm{MPa}$ and an elongation at break of 525\%) which can contribute to improve toughness of PLA.

Two cottonseed oil derivatives, i.e. epoxidized cottonseed oil (ECSO) and maleinized cottonseed oil (MCSO) were used as compatibilizers, and compared with an epoxy styrene-acrylic oligomer, i.e. Joncryl ${ }^{\circledR}$. The cottonseed oil (CSO) was supplied by Sigma Aldrich Spain (Madrid, Spain). Its main properties are a density of $0.92 \mathrm{~g} \cdot \mathrm{cm}^{-3}$ and an iodine index comprised in the 109-120 range, which allows chemical modification. Joncry ${ }^{\circledR}$ ADR-4368 was supplied by BASF S.A (Barcelona, Spain) and is characterized by a $T_{\mathrm{g}}$ of $54^{\circ} \mathrm{C}$, an epoxy equivalent weight of $285 \mathrm{~g} \cdot \mathrm{mol}^{-1}$ and a molecular weight, $M_{\mathrm{w}}$ of $6800 \mathrm{~g} \cdot \mathrm{mol}^{-1}$. The cottonseed oil was subjected to epoxidation [40] and maleinization as reported in previous works [37]. The most relevant parameters obtained after the corresponding chemical processes are as follows. With regard to ECSO, the oxirane oxygen index was 5.32 after $8 \mathrm{~h}$. Regarding MCSO an acid value of $63.72 \mathrm{mg} \mathrm{KOH} \mathrm{g}^{-1}$ was obtained after $3 \mathrm{~h}$ reaction. Figure 1 shows a schematic representation of the base polymers and the compatibilizer additives.

\subsection{Manufacturing of PLA/PBAT films}

PLA/PBAT blends were manufactured with different compositions as summarized in Table 1 . The amount of Joncryl ${ }^{\circledR}$ was set to $1 \mathrm{wt} \%$ as the manufacturer recommends an additive load comprised between $0.25-2 \mathrm{wt} \%$. With regard to the cottonseed oil derivatives, two different loads were used, i.e. 1 and $7.5 \mathrm{wt} \%$ as previous results have suggested [35, 37]. PLA was dried for $24 \mathrm{~h}$ at $60^{\circ} \mathrm{C}$ while PBAT was dried overnight at $40^{\circ} \mathrm{C}$. All materials were processed by extrusion in a DSM Xplore MC 15 micro compounder at $180^{\circ} \mathrm{C}$. The pre-mixing time inside the plasticization chamber was set to $3 \mathrm{~min}$ at a rotating speed of $100 \mathrm{rpm}$. After this time, the compounded material was forced to exit the plasticization chamber and extruded through a nozzle connected to a chill-roll system to obtain a continuous film, $30 \mathrm{~mm}$ width and $30 \mu \mathrm{m}$ thick films at $15 \mathrm{rpm}$ and a controlled force of $700 \mathrm{~N}$.

\subsection{Mechanical characterization}

Mechanical characterization was carried out as indicated according to the ISO 527-3 standard in a universal test machine LLOYD $30 \mathrm{~K}$ (Hampshire, England). Samples (type 2) were tested at a crosshead speed rate of $5 \mathrm{~mm} \cdot \mathrm{min}^{-1}$ with a load cell of $500 \mathrm{~N}$. The samples sized $160 \mathrm{~mm}$ in length, $20 \mathrm{~mm}$ width and an average thickness of $30 \mu \mathrm{m}$. Special grips for thin films supplied by LLOYD (TG series) were used to appropriate characterize films avoiding premature fracture due to the clamp force. These grips are used for tensile testing of thin materials such as paper, rubber, thin plastic films, woven and non-woven textiles. At least five parallel samples were tested at room temperature and average values of the main parameters were calculated.

\subsection{Morphological characterization}

The fracture surface obtained by cryofracture (longitudinal to the extrusion direction) was observed in 


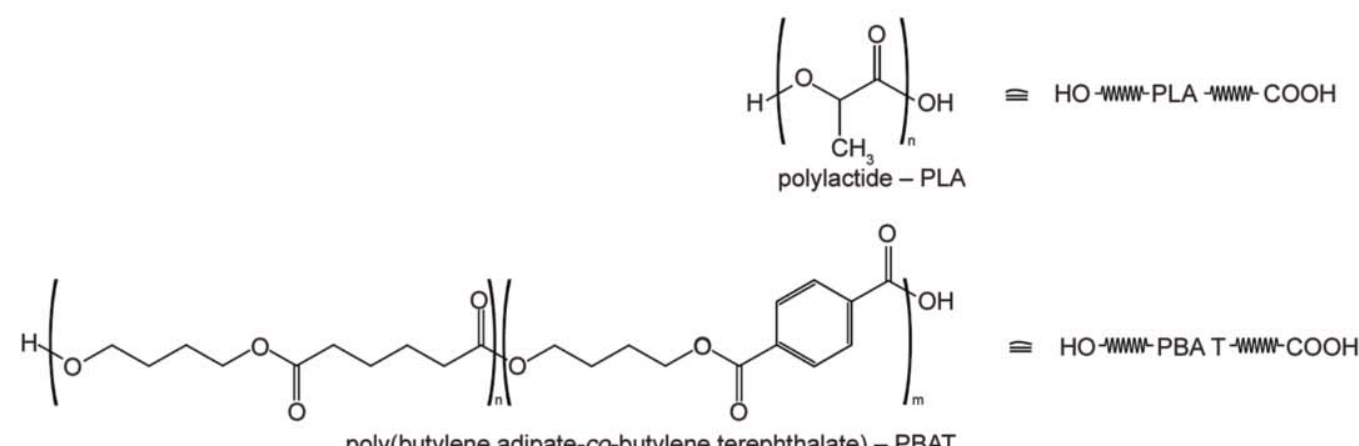

a)

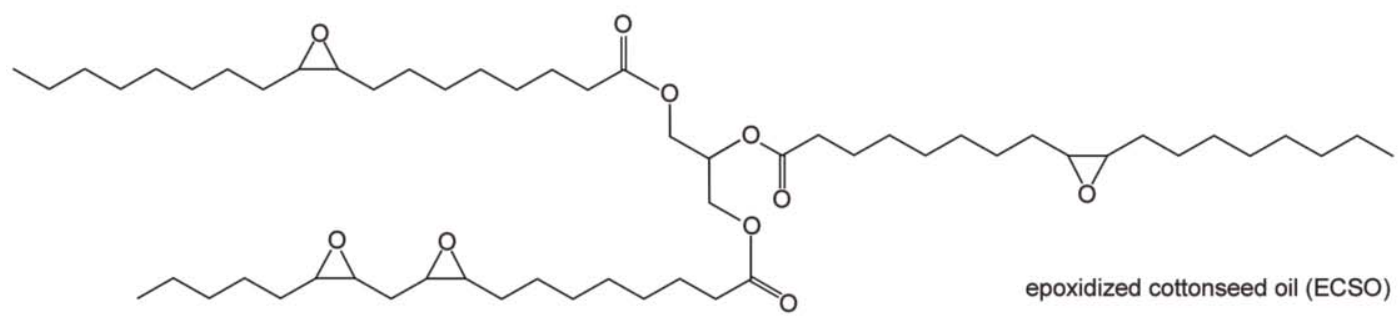

b)

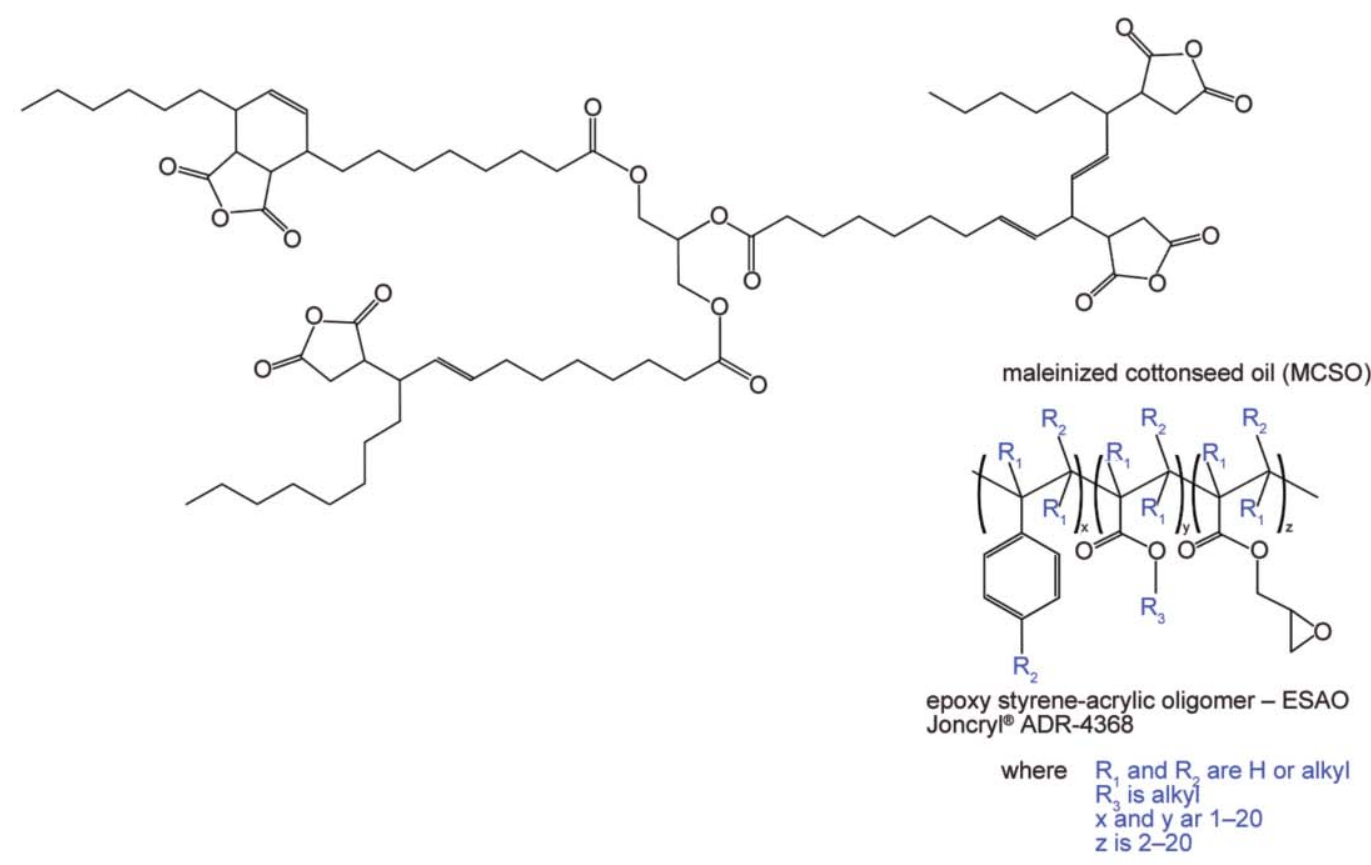

Figure 1. Schematic representation of the chemical structure of a) base polymers, i.e. poly(lactic acid) - PLA and poly(butylene adipate-co-terephthalate) - PBAT and b) epoxidized cottonseed oil - ECSO, maleinized cottonseed oil MCSO and epoxy styrene-acrylic oligomer Joncryl ${ }^{\circledR}$ (generic structure).

a field emission scanning electron microscope, FESEM Zeiss Ultra from Oxford Instruments at an acceleration voltage of $2 \mathrm{kV}$. An ultrathin metallic layer of platinum was sputtered on the fractured films in a sputter coater EM MED020 from Leica Microsystems.

\subsection{Thermal and thermomechanical characterization of PLA/PBAT films}

The most relevant thermal transitions were obtained by differential scanning calorimetry (DSC) in a Mettler-Toledo DSC mod. 821 (Schwerzenbach, Switzerland). The DSC runs were programmed into three 
Table 1. Composition and coding of PLA/PBAT binary blends compatibilized with cottonseed oil derivatives.

\begin{tabular}{|c|c|c|c|c|c|}
\hline Code & $\begin{array}{c}\text { PLA } \\
\text { [wt\%] }\end{array}$ & $\begin{array}{l}\text { PBAT } \\
\text { [wt\%] }\end{array}$ & $\begin{array}{c}\text { Joncryl }^{\circledR} \\
\text { [wt } \%]^{\text {B }}\end{array}$ & $\begin{array}{l}\text { ECSO } \\
{[w t \%]}\end{array}$ & $\begin{array}{l}\text { MCSO } \\
{[w t \%]}\end{array}$ \\
\hline PLA & 100.0 & - & - & - & - \\
\hline PBAT & - & 100.0 & - & - & - \\
\hline PLA/PBAT & 80.0 & 20.0 & - & - & - \\
\hline PLA/PBAT/1 ECSO & 79.2 & 19.8 & - & 1.0 & - \\
\hline PLA/PBAT/7.5 ECSO & 74.0 & 18.5 & - & 7.5 & - \\
\hline PLA/PBAT/1 MCSO & 79.2 & 19.8 & - & - & 1.0 \\
\hline PLA/PBAT/7.5 MCSO & 74.0 & 18.5 & - & - & 7.5 \\
\hline PLA/PBAT/1 Joncryl ${ }^{\circledR}$ & 79.2 & 19.8 & 1.0 & - & - \\
\hline
\end{tabular}

stages: first a heating from -25 to $200^{\circ} \mathrm{C}$; then a cooling process down to $-25^{\circ} \mathrm{C}$ and a final heating stage up to $200^{\circ} \mathrm{C}$ again. All three stages used the same heating rate of $10^{\circ} \mathrm{C} \cdot \mathrm{min}^{-1}$ and were run under nitrogen atmosphere $\left(66 \mathrm{~mL} \cdot \mathrm{min}^{-1}\right)$. The degree of crystallinity $\left(\chi_{\mathrm{c}}[\%]\right)$ was calculated from the second DSC heating runs using Equation (1):

$\chi_{\mathrm{c}}[\%]=100 \cdot \frac{\Delta H_{\mathrm{m}}-\Delta H_{\mathrm{cc}}}{\Delta H_{\mathrm{m}}(100 \%)} \cdot \frac{1}{W_{\mathrm{PLA}}}$

where $\Delta H_{\mathrm{m}}$ and $\Delta H_{\mathrm{cc}}$ stand for the melt and cold crystallization enthalpies respectively $\left[\mathrm{J} \cdot \mathrm{g}^{-1}\right]$. On the other hand, $\Delta H_{\mathrm{m}}(100 \%)$ represents the melt enthalpy of a theoretical fully crystalline PLA $\left(93 \mathrm{~J} \cdot \mathrm{g}^{-1}\right)$ [21] and $W_{\text {PLA }}$ is the wt $\%$ PLA in the blend. With regard to the glass transition temperature, ISO 113572:2015 was used. From the methods described in this standard, the inflection point was considered as the $T_{\mathrm{g}}$ value of all developed materials. In this method, the $T_{\mathrm{g}}$ value is assigned to the maximum of the derivative DSC curve or the temperature with the maximum slope in the glass transition area.

Thermal degradation at high temperatures was followed by thermogravimetric (TGA) analysis. Samples with an average weight of about 5-7 mg were placed in standard alumina pans and subjected to a heating program from 30 up to $660^{\circ} \mathrm{C}$ at a heating rate of $20^{\circ} \mathrm{C} \cdot \mathrm{min}^{-1}$ in a Mettler-Toledo TGA/ SDTA $851 \mathrm{e} / \mathrm{SF} / 1100$ thermobalance in nitrogen atmosphere. In addition to the TGA thermograms, two representative temperatures, were calculated: $T_{5 \%}$ and $T_{50 \%}$ which correspond to temperatures at which a 5 and a $50 \mathrm{wt} \%$ loss occurs, respectively.

Thermomechanical characterization of PLA/PBAT films was carried out in an oscillatory rheometer AR G2 from TA Instruments equipped with a special clamp system for solid samples working in a combined shear-torsion mode. Samples of $10 \times 20 \mathrm{~mm}^{2}$ with an average thickness of $30 \mu \mathrm{m}$, were subjected to a temperature sweep from -40 up to $100^{\circ} \mathrm{C}$ at a heating rate of $2{ }^{\circ} \mathrm{C} \cdot \mathrm{min}^{-1}$. The selected frequency was $1 \mathrm{~Hz}$ and the normal force was $0.02 \mathrm{~N}$ while the maximum deformation was maintained at $1 \%(\% \gamma)$.

\subsection{Surface characterization of PLA/PBAT films}

The wetting properties of the developed blends were obtained by contact angle measurements in a Krüss goniometer model FM140 from KRÜSS GmbH (Hamburg, Germany). Five water droplets were deposited onto the film surface and the corresponding contact angle was measured after $30 \mathrm{~s}$ to obtain stabilized values. Prior to contact angle characterization, sample films were dried at $40^{\circ} \mathrm{C}$ for $24 \mathrm{~h}$.

In addition, the color properties of the developed films were characterized in a Hunter Mod. CFLXDIF-2 colorimeter from Hunterlab (Murnau, Germany). Although the apparatus can provide different measurements, only the luminance $\left(L^{*}\right)$ was measured to evaluate the change in transparency.

\subsection{Disintegration in controlled compost soil of PLA/PBAT films}

Disintegration tests were conducted on squared samples $\left(25 \times 25 \mathrm{~mm}^{2}\right)$ with an average thickness of $30 \mu \mathrm{m}$ under the recommendations of the ISO 20200. Samples were placed into an aerobic reactor with a synthetic waste manufactured as indicated in ISO 20200. Before placing samples into the reactor, all films were dried at $40^{\circ} \mathrm{C}$ for $24 \mathrm{~h}$. Then, the films were buried into the compost soil and extracted at $6,8,9,10,11$, 14, 16, 21 and 23 days, washed with distilled water and dried at $40{ }^{\circ} \mathrm{C}$ for a day. Finally, optical images were taken to follow the disintegration process. 


\section{Results and discussion}

\subsection{Effect of compatibilizers on mechanical properties of PLA/PBAT films}

Figure 2 shows the main results obtained with the herein-developed PLA/PBAT blends. As it can be seen, neat PLA is quite brittle with a modulus of $3145 \mathrm{MPa}$ and a tensile strength of 54.5 MPa. Regarding its ductility, its elongation at break is close to $29.2 \%$ (in film form).

These features limit the use of PLA in the packaging industry in which flexible films are required. On the other hand, PBAT is an extremely ductile polymer with a modulus of $96.4 \mathrm{MPa}$ and a tensile strength of 26.2 MPa. In contrast, its elongation at break reaches values of $307.6 \%$ thus giving clear evidences of its flexibility. For this reason, blends of PLA with PBAT are expected to be more flexible. As it can be seen in the above-mentioned figures, the uncompatibilized PLA/PBAT blend containing $20 \mathrm{wt} \%$ PBAT shows an increased elongation at break of $59.0 \%$ with interesting mechanical resistant properties, i.e. a Young modulus of $2079 \mathrm{MPa}$ and a tensile strength of $39.9 \mathrm{MPa}$. The addition of $1 \mathrm{wt} \%$ Joncry ${ }^{\circledR}$ gives similar mechanical resistance properties (modulus and tensile strength) while the elongation at break is remarkably improved up to $83.7 \%$ compared to the uncompatibilized blend. These results give clear evidences of the compatibilization effects that Joncryl ${ }^{\circledR}$ can provide to polyesters. Specifically, the compatibilization is achieved by the reaction of the epoxy groups in Joncryl ${ }^{\circledR}$ oligomers and the hydroxyl terminal groups in polyesters (See Figure 3a) leading to chain extension and potential crosslinking. Racha Al-Itry et al. [29] reported similar results with a PLA/ PBAT blend with an elongation at break of $50 \%$ which was increased up to $135 \%$ with the addition of $0.5 \mathrm{wt} \%$ Joncryl ${ }^{\circledR}$. Addition of $1 \mathrm{wt} \%$ of both ECSO and MCSO leads to an increase in elongation at break with values of 70.0 and $60.5 \%$ respectively but this increase is not as high as that observed with Joncryl ${ }^{\circledR}$. Nevertheless, it is worthy to note that both $1 \mathrm{wt} \%$ ECSO and MCSO provide improved mechanical resistant properties with tensile strength values of 52.9 and 45.0 MPa respectively which are noticeable higher than those of Joncryl ${ }^{\circledR}$ (39.9 MPa). This suggests that both ECSO and MCSO (even at very low concentrations) provide a plasticizing effect but due to the triglyceride structure, not only chain extension but also branching and somewhat crosslinking, can occur as shown in Figure 3b. It has been reported that small amounts of modified vegetable oils can slightly plasticize PLA and other polyesters. Nevertheless, the efficiency of vegetable oil-based plasticizers is very poor as, in general, a very slight decrease on the glass transition temperature is achieved. Nevertheless, the highly reactive groups in modified vegetable oils (mainly epoxy, acrylate, maleic anhydride groups, among others) can react with hydroxyl groups present in the end chains of polyesters thus leading to additional reactions that could lead to

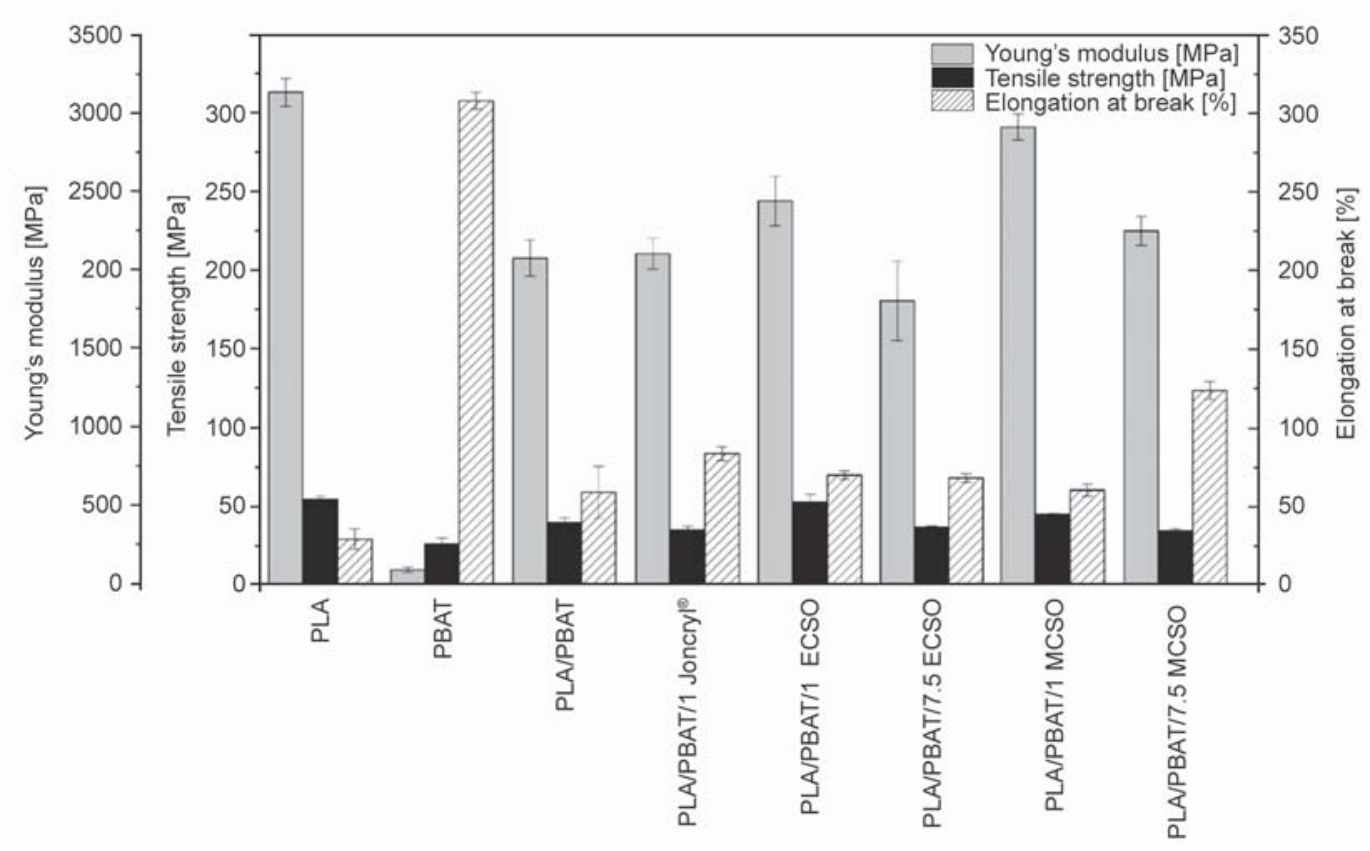

Figure 2. Comparative bar plot of tensile properties, i.e. Young's modulus, tensile strength and elongation at break, of neat PLA, neat PBAT and PLA/PBAT blends with and without compatibilizers. 
a)

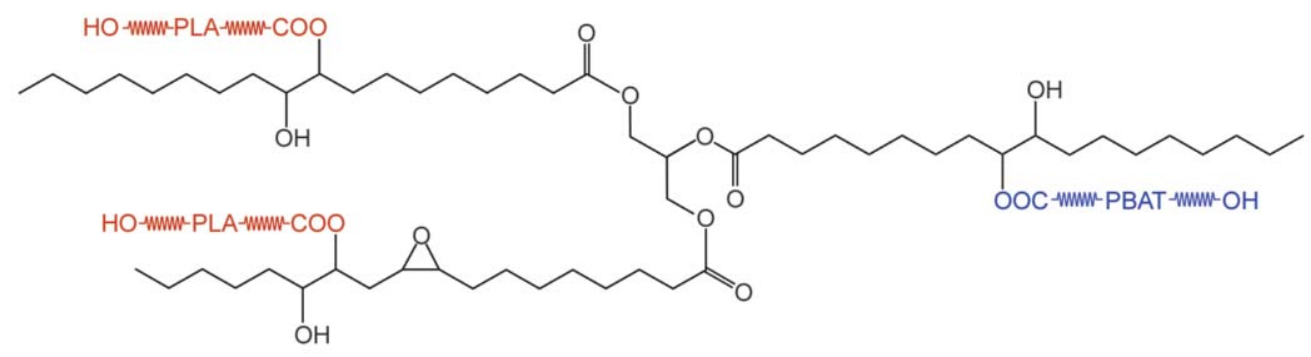

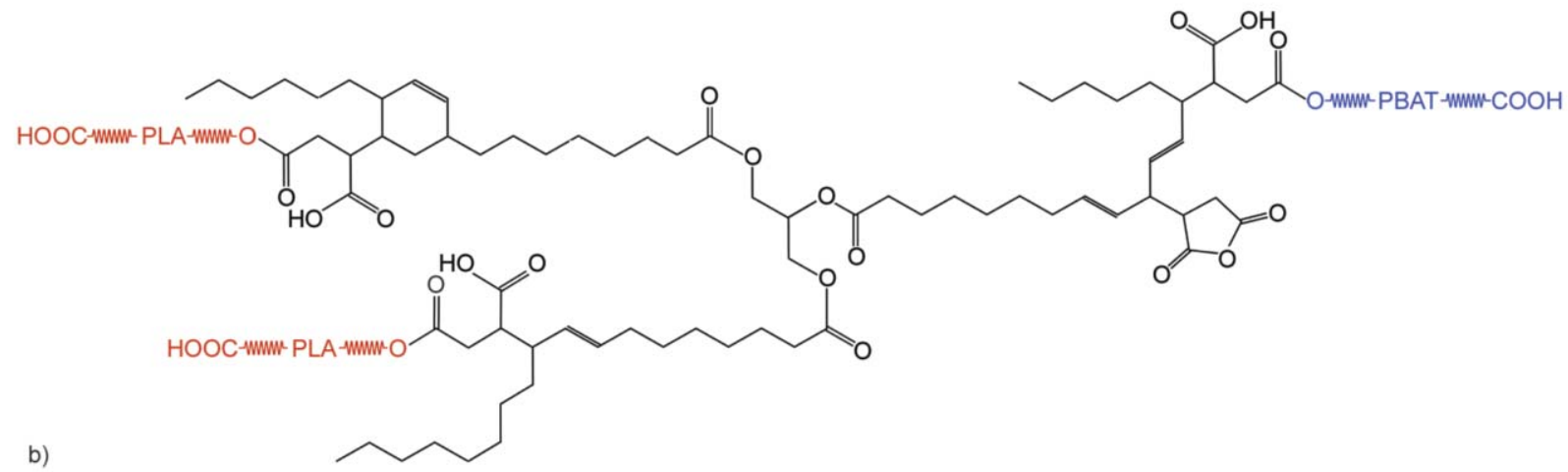

b)

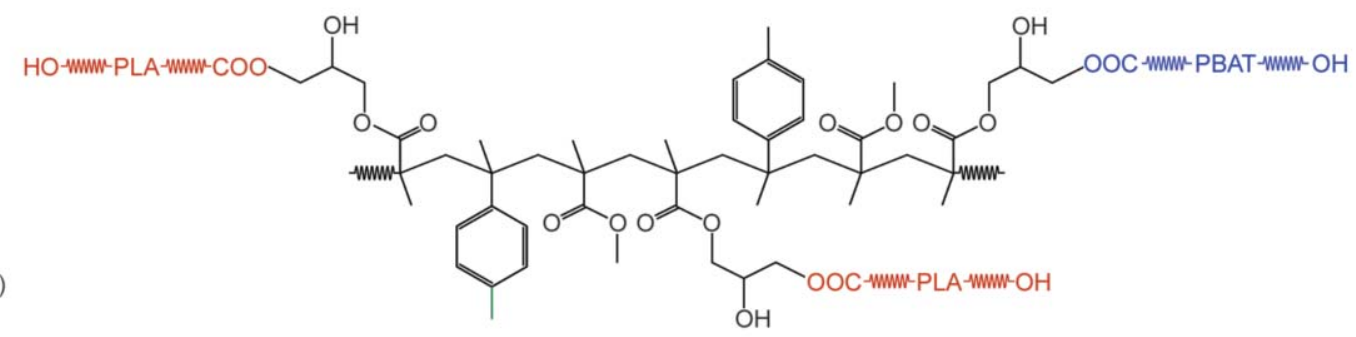

Figure 3. Schematic representation of a) ECSO compatibilized PLA/PBAT blend, b) MCSO compatibilized PLA/PBAT blend and c) Joncryl ${ }^{\circledR}$-compatibilized PLA/PBAT blend.

chain extension, branching and crosslinking simultaneously as reported by Quiles-Carrillo and coworkers [41-43] in several works. With regard to Joncryl ${ }^{\circledR}$, typical amounts of $1 \mathrm{wt} \%$ are recommended by suppliers to avoid gel formation by crosslinking. So that, it is expectable a more intense overlapping of chain extension, branching and crosslinking when using ECSO and MCSO than in the case of Joncryl ${ }^{\circledR}$ (Figure 3c). A FTIR study carried out by Quiles-Carrillo et al. [43] on poly(lactic acid) with lignocellulosic fillers demonstrated the reaction between maleinized linseed oil (MLO) and hydroxyl groups in PLA end chains and cellulose particles therefore giving clear evidences of reactive extrusion.

\subsection{Effect of compatibilizers on the morphology of PLA/PBAT films}

The addition of $7.5 \mathrm{wt} \%$ ECSO does not provide any improvement on mechanical ductility nor mechanical resistance. Nevertheless, PLA/PBAT blend compatibilized with $7.5 \mathrm{wt} \%$ MCSO offers the maximum elongation at break of all developed formulations, reaching values of $123.0 \%$ without compromising in a remarkable way other mechanical resistance properties such as modulus and tensile strength. Figure 4 shows some evidences of the compatibilizing effect of the different additives used in this study. It has been reported that PLA/PBAT system can show miscibility, partial miscibility or even, immiscibility [44] with $20 \mathrm{wt} \%$ PBAT. As it can be observed in Figure 4b, PLA/PBAT does not show the typical droplet-like structure of immiscible polymer blends but DSC and DMA results suggest poor miscibility as it will be discussed later. It is possible to expect that PBAT-rich domains are very small. On the other hand, neat PLA (Figure 4a) shows a smooth surface typical of a brittle fracture. Addition of $1 \mathrm{wt} \%$ of the different compatibilizers provides some differences. The PLA/ PBAT blend compatibilized with $1 \mathrm{wt} \%$ ECSO (Figure 4d) shows a smooth fracture surface similar to that of the PLA/PBAT blend and some small spherical domains can be detected, while PLA/PBAT blends compatibilized with Joncryl ${ }^{\circledR}$ or MCSO show presence of cavities/voids and filaments in the longitudinal 

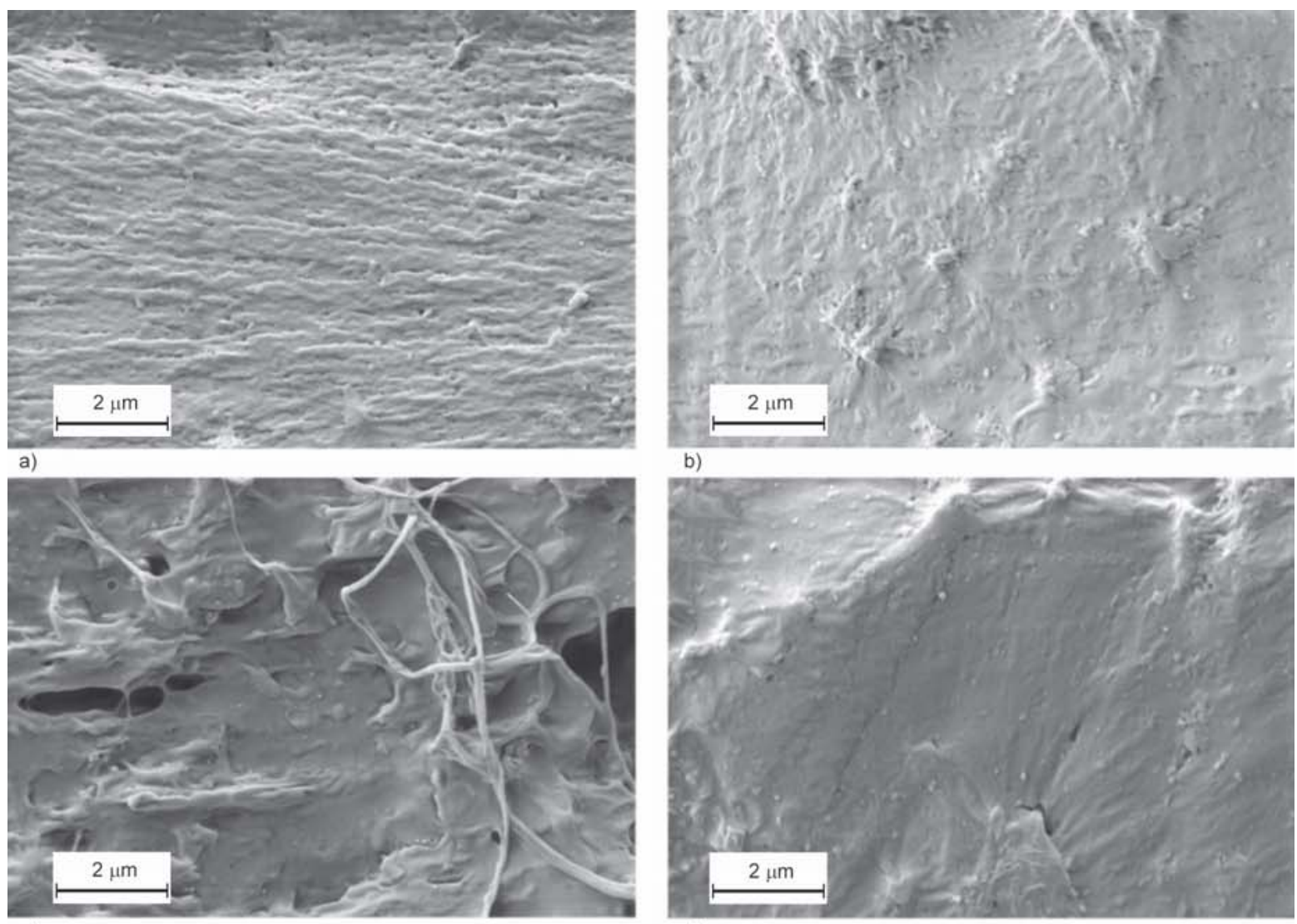

b)
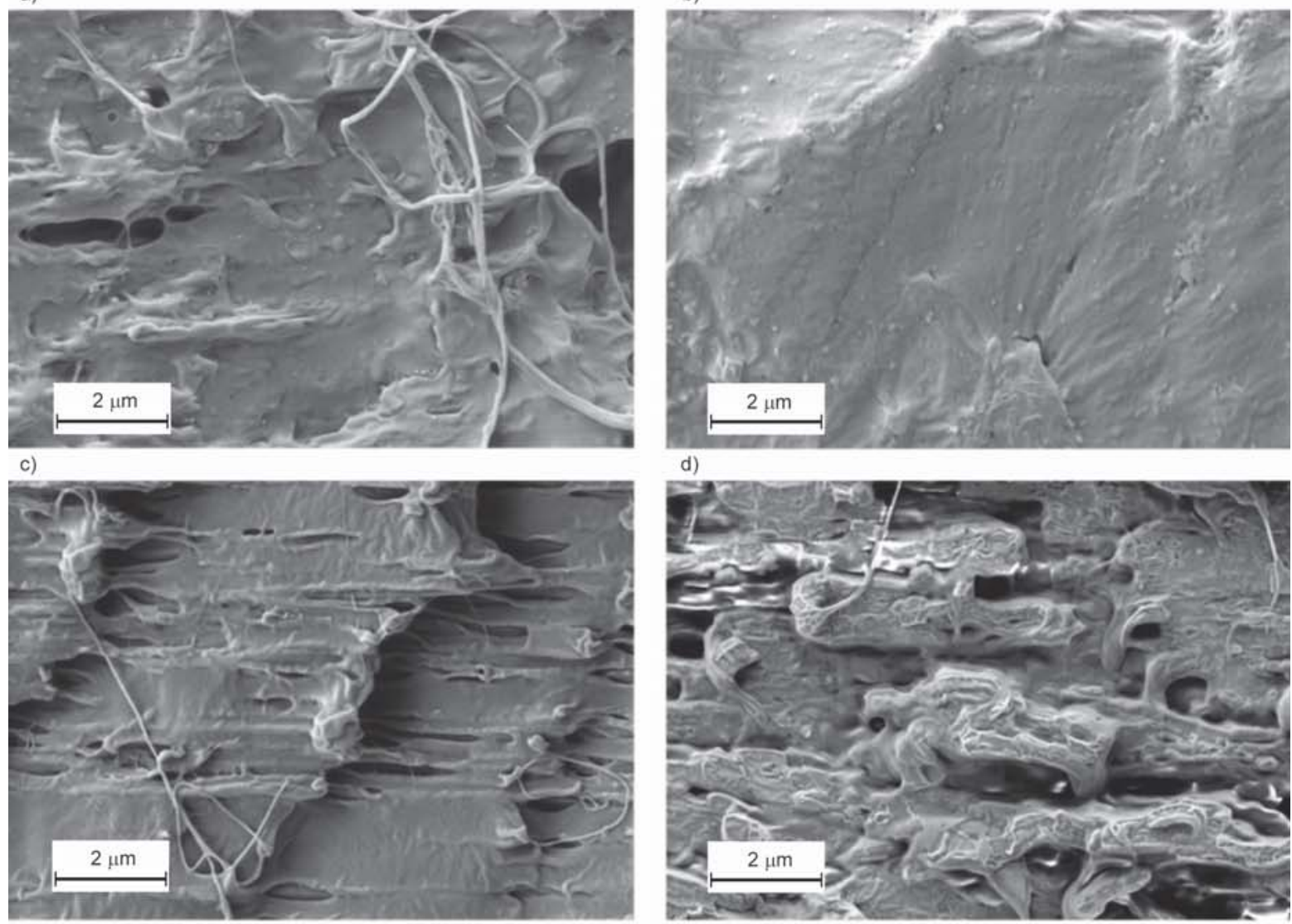

d)

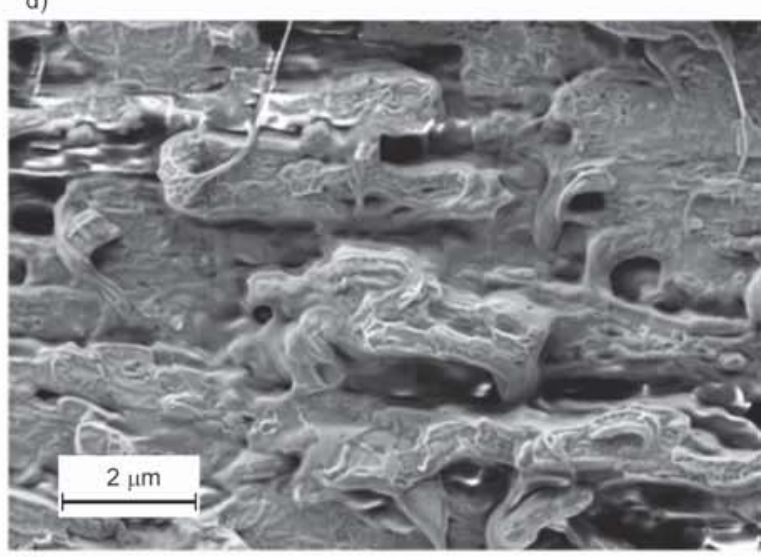

f)

e)

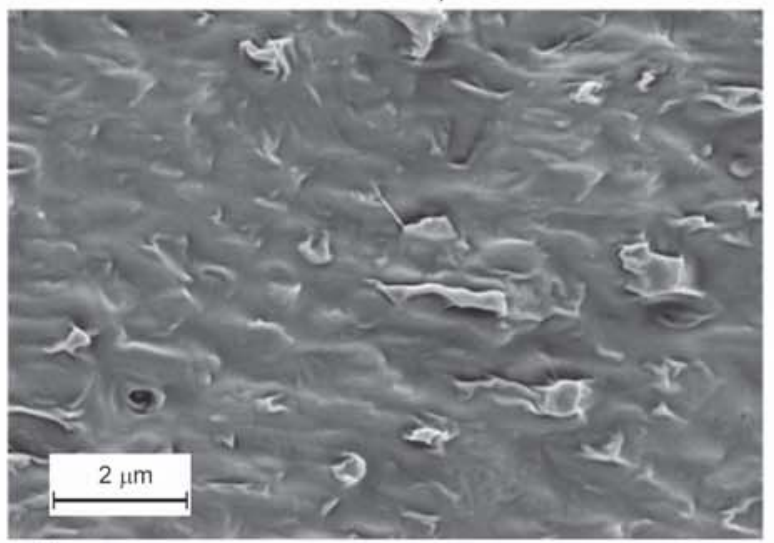

g)

Figure 4. FESEM images of the cryofractured films at 10000 $\times$, a) neat PLA b) uncompatibilized PLA/PBAT c) PLA/PBAT (80/20 wt/wt) compatibilized with $1 \mathrm{wt} \% \mathrm{Joncryl}^{\circledR}$, d) PLA/PBAT (80/20 wt/wt) compatibilized with $1 \mathrm{wt} \%$ ECSO e) PLA/PBAT (80/20 wt/wt) compatibilized with $1 \mathrm{wt} \%$ MCSO, f) PLA/PBAT (80/20 wt/wt) compatibilized with $7.5 \mathrm{wt} \%$ ECSO and g) PLA/PBAT (80/20 wt/wt) compatibilized with $7.5 \mathrm{wt} \% \mathrm{MCSO}$. 
(extrusion) direction. Phase separation has been reported for vegetable oil-derived additives over $5 \mathrm{wt} \%$ as small spherical domains due to excess plasticizer/ compatibilizer [45]. Nevertheless the PLA/PBAT system shows a heterogeneous fracture surface, even for the ECSO- and MCSO-compatibilized blends with $7.5 \mathrm{wt} \%$ compatibilizer (Figure $4 \mathrm{f}$ and $4 \mathrm{~g}$ ) which suggests phase separation as well. Despite this, the fracture surface of the ECSO-compatibilized PLA/PBAT blend (Figure 4f) shows strong heterogeneity which can be related to phase separation while the MCSOcompatibilized blend (Figure 4g), offers a more homogeneous fracture surface which could be responsible for the maximum elongation at break achieved.

\subsection{Effect of compatibilizers on thermal properties of PLA/PBAT films}

Figure 5 shows the DSC profiles of the neat polymers, namely PLA and PBAT during the second heating stage, while Figure 6 gathers the comparative DSC thermograms of PLA/PBAT blends without and with several compatibilizers.

The glass transition temperature $\left(T_{\mathrm{g}}\right)$ of neat PLA can be clearly observed in Figure 5 as a step in the base line located at $59.1^{\circ} \mathrm{C}$. The glass transition temperature of PBAT cannot be observed in the temperature range covered by the DSC temperature program as it is located below room temperature. With regard to the melt peak temperature, PLA and PBAT melt at 147.8 and $123.1^{\circ} \mathrm{C}$ respectively. In addition, PLA shows a cold crystallization (endothermic peak) between the $T_{\mathrm{g}}$ and the melt process, with a peak temperature $\left(T_{\mathrm{cc}}\right)$ located at $117.7^{\circ} \mathrm{C}$. The glass transition

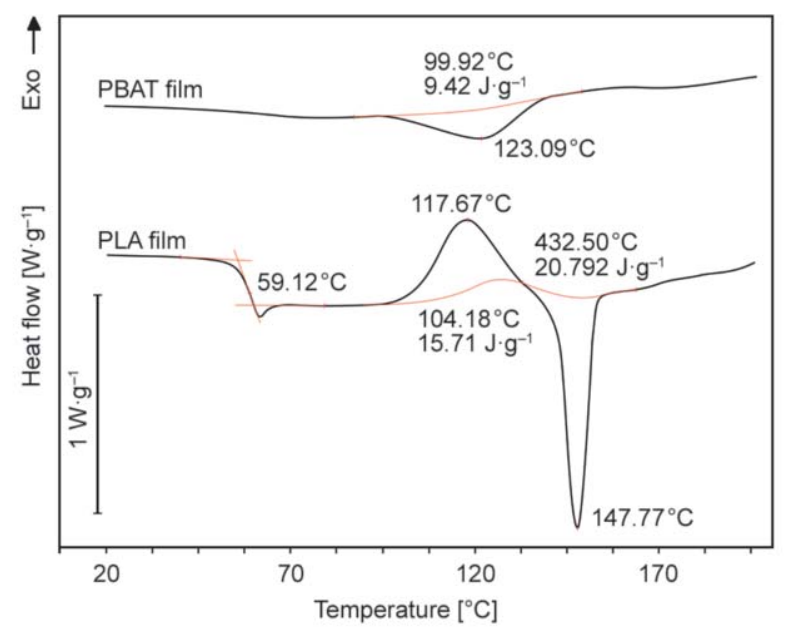

Figure 5. Differential scanning calorimetry (DSC) thermograms for neat PLA and PBAT. temperature for PBAT was determined by DMA and was $-22.9^{\circ} \mathrm{C}$.

Some miscibility between PLA and PBAT polymer chains can be expected as the Tg for the uncompatibilized blend is slightly lower $\left(58.8^{\circ} \mathrm{C}\right)$. In a similar way, the study by Abdelwahab et al. [46] revealed poor miscibility between these two polymers as indicated by DSC characterization. In particular, they only observed a decrease in the $T_{\mathrm{g}}$ of neat PLA of $0.25^{\circ} \mathrm{C}$ for a PLA/PBAT blend containing $30 \mathrm{wt} \%$ PBAT. The addition of all three compatibilizers, whatever their amount, led to an additional decrease in $T_{\mathrm{g}}$. In the case of Joncry ${ }^{\circledR}$, addition of $1 \mathrm{wt} \%$ to the PLA/PBAT blend led to a decrease of almost $1.3^{\circ} \mathrm{C}$ as obtained by DSC. Abdelwahab et al. [46] reported negligible changes in $T_{\mathrm{g}}$ in PLA/PBAT blends with $20 \mathrm{wt} \%$ organosolv lignin (OL) and different Joncryl ${ }^{\circledR}$ loading. With regard to the vegetable oilderived compatibilizers, it has been proved that their plasticization effects are not as pronounced as typical primary plasticizers. Nevertheless, vegetable-oil derived compatibilizers exert a dual function: on one hand, they promote chain extension due to reaction of epoxide rings or maleic anhydride groups with hydroxyl terminal groups in both PLA and PBAT polyesters. On the other hand, they contribute to compatibilization as they can react with both PLA and PBAT polymeric chains, acting as a bridge between the two immiscible (or low miscibility) polymers. Vegetable oil derivatives, with the triglyceride structure, provide increased free volume and this has a positive effect on chain mobility $[35,37]$. It is, in fact, the

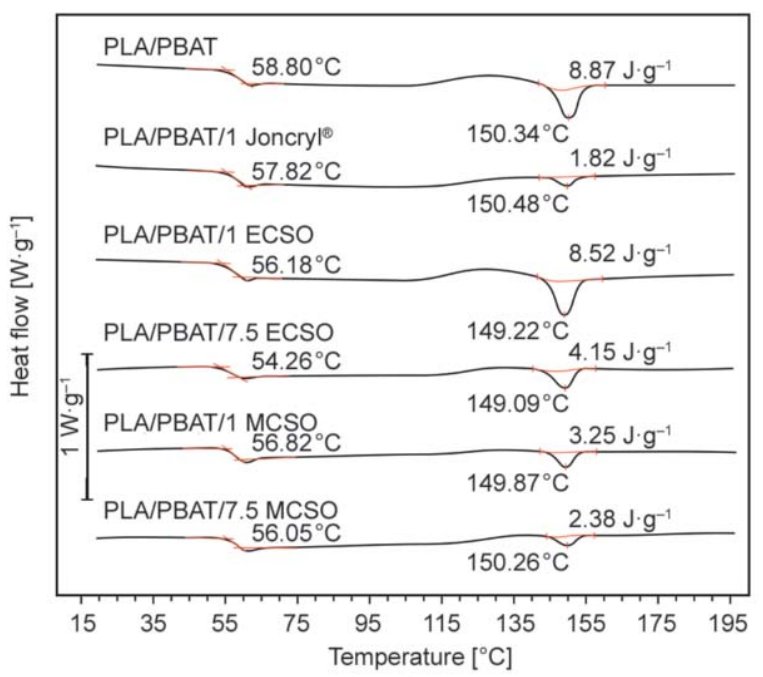

Figure 6. Comparative plot of the DSC thermograms of uncompatibilized PLA/PBAT blend (80/20 wt/wt) and the same blend compatibilized with different amounts of Joncryl ${ }^{\circledR}$, ECSO and MCSO. 
PLA/PBAT blend with $7.5 \mathrm{wt} \% \mathrm{MCSO}$ which reaches the lowest $T_{\mathrm{g}}$ values among all the formulations in this study $\left(56.1^{\circ} \mathrm{C}\right)$. The main advantage of vegetable oil-derived compatibilizers/plasticizers is that the elongation at break is remarkably increased but, in contrast, other mechanical resistance properties are not reduced in a great extent.

With regard to the crystallinity, it is worthy to note that neat PLA possesses a $\chi_{\mathrm{c}} \%$ of $5.46 \%$. Although it seems that the cold crystallization process decreases in the blend, it is important to remark that both the cold crystallization of PLA and the melt process of PBAT occur in a similar temperature range (see Figure 5). As these two energetically opposite processes are overlapped, it is not appropriate to calculate the degree of crystallinity of PLA in the uncompatibilized and compatibilized blends. It could be possible to separate these processes by using modulated signal.

PLA/PBAT films were also characterized by dynamic mechanical thermal analysis (DMA). This is a more sensitive technique to obtain the $T_{\mathrm{g}}$ values and measure mechanical properties, i.e. storage modulus $\left(G^{\prime}\right)$ and damping factor $(\tan \delta)$ in dynamic conditions. Figure 7 gathers the DMA of neat PLA, PBAT and their blend $(80 / 20 \mathrm{wt} / \mathrm{wt})$ without and with different compatibilizers. As it can be seen, the uncompatibilized PLA/PBAT blend shows a slight decrease in $T_{\mathrm{g}}$ from $66.3^{\circ} \mathrm{C}$ (neat PLA) down to $65.0^{\circ} \mathrm{C}$. This is representative for very low miscibility between the two blend components. Al-Itry et al. [47] observed similar decrease in $T_{\mathrm{g}}$ when $20 \mathrm{wt} \%$ PBAT was added to PLA. Specifically, the $T_{\mathrm{g}}$ was reduced by $1{ }^{\circ} \mathrm{C}$ with regard to unblended PLA. Addition of $1 \mathrm{wt} \%$ of the three compatibilizers used in this study led to a slight decrease in $T_{\mathrm{g}}$ of about $2{ }^{\circ} \mathrm{C}$ which indicates some compatibilizing/plasticization behavior but these two phenomena are overlapped. Once again, the highest reduction in the $T_{\mathrm{g}}$ is obtained with high vegetable oil-derived compatibilizer. In particular, the $T_{\mathrm{g}}$ decreases down to 62.2 and $62.6^{\circ} \mathrm{C}$ in blends with $7.5 \mathrm{wt} \%$ ECSO and MCSO respectively. Nevertheless, the most relevant information regarding the effect of all used compatibilizers can be observed by following the evolution of the storage modulus, $G^{\prime}$. Neat PLA is the stiffer material with a $G^{\prime}$ value of about $2500 \mathrm{MPa}$. Obviously, neat PBAT is an extremely flexible polymer with a very low $G^{\prime}$ value at $30^{\circ} \mathrm{C}$ of about $100 \mathrm{MPa}$. With regard to the uncompatibilized PLA/PBAT blend, the $G^{\prime}$ at $30^{\circ} \mathrm{C}$
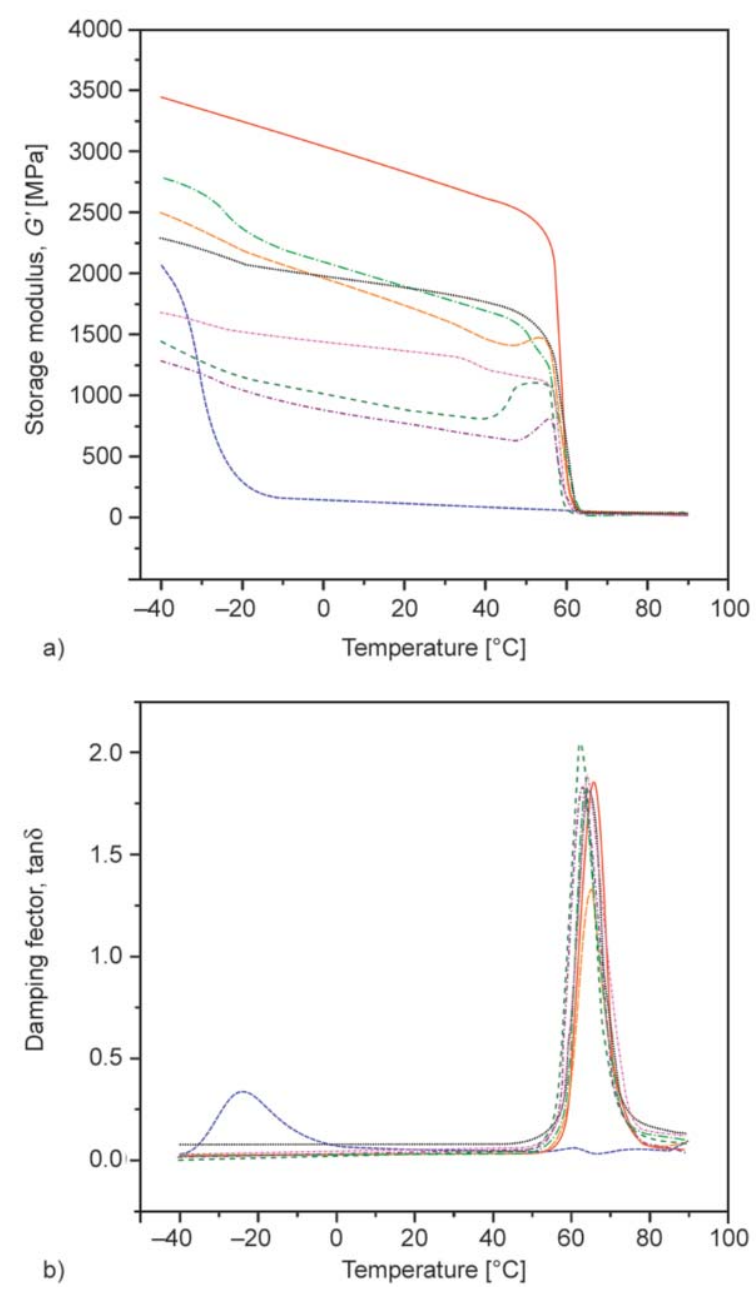

Figure 7. Plot comparison of a) storage modulus, $G^{\prime}$ and b) damping factor, $\tan \delta$ of neat PLA, PBAT and PLA/PBAT blend (80/20 wt/wt) without and with different compatibilizers.

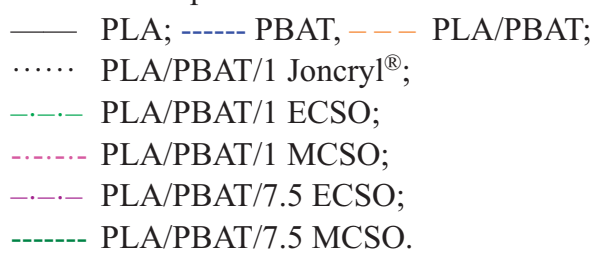

is close to $1650 \mathrm{MPa}$ thus showing the flexibilization effect of PBAT on PLA/PBAT blends. ECSO seems to be more reactive as the corresponding compatibilized blend with $1 \mathrm{wt} \%$ ECSO shows a $G^{\prime}$ value of $1750 \mathrm{MPa}$ at $30^{\circ} \mathrm{C}$ which is similar to the Joncrylcompatibilized blend (1800 MPa). MCSO seems to give more flexible materials with $G^{\prime}$ values at $30^{\circ} \mathrm{C}$ of 1300 and $950 \mathrm{MPa}$ for 1 and $7.5 \mathrm{wt} \% \mathrm{MCSO}$ content in PLA/PBAT blends. All these results are in total agreement with the previous mechanical properties. Although $G^{\prime}$ suggests the $T_{\mathrm{g}}$ of the PBAT rich phase (decrease in $G^{\prime}$ at about $-20^{\circ} \mathrm{C}$ ), the corresponding damping factor peaks are not detectable. It is important to take into account that $G^{\prime}$ is plotted in 

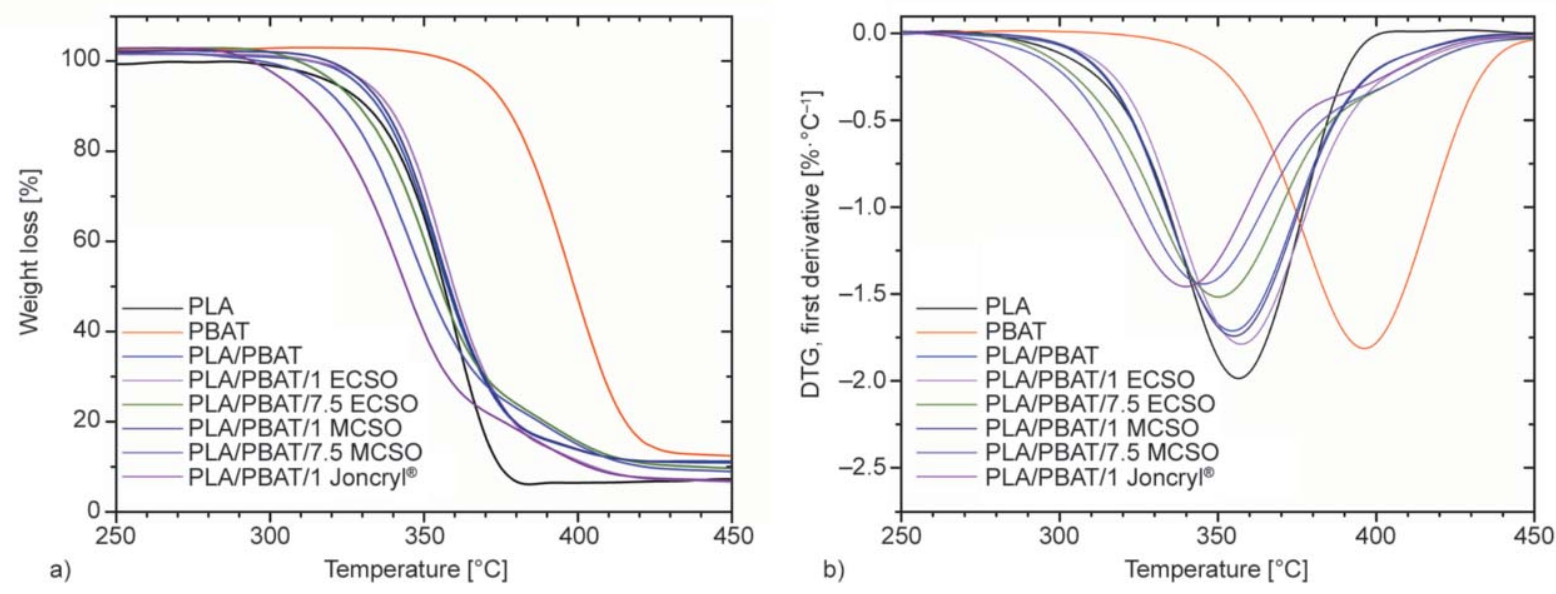

Figure 8. Comparative plot of the TGA thermograms of neat PLA, PBAT and PLA/PBAT blend (80/20 wt/wt) without and with different compatibilizers, a) TGA and b) first derivative DTG.

a decimal scale (not logarithmic) and this change is less pronounced in a logarithmic scale.

One important issue to take into account in these formulations is their thermal stability. As it can be seen in Figure 8, both vegetable oil-derived additives contribute to an improvement on overall thermal stability while Joncryl ${ }^{\circledR}$ does not provide any relevant increase in thermal stability. This could be related to the particular thermal stability of vegetable oils and the flexibility they provide to the compatibilized structure. In fact, one of the main uses of modified vegetable oils, is as secondary plasticizers in poly (vinyl chloride) - PVC industrial formulations as these can act as free radical scavengers thus leading to increased thermal stability. In fact, PVC is extremely sensitive to thermal degradation and presence of modified vegetable oils leads to improved thermal stability [8]. As suggested by TGA analysis, Joncryl seems to slightly decrease the thermal stability as it probably, cannot act as a free radical scavenger.

The main parameters obtained by TGA analysis are summarized in Table 2 with the temperature values corresponding to 5 and $50 \mathrm{wt} \%$ loss, $T_{5 \%}$ and $T_{50 \%}$ respectively.

As it can be seen, the simple addition of PBAT in the uncompatibilized blend, gives increased thermal stability. The onset degradation temperature, measured at $5 \mathrm{wt} \%$ loss, changes from 321.2 up to $328.2^{\circ} \mathrm{C}$. Similar findings were reported by Lu et al. [48] that observed an increase of $11.2^{\circ} \mathrm{C}$ in thermal stability of PLA with addition of $30 \mathrm{wt} \%$ PBAT. It is also worthy to note the additional stabilization that ECSO and MCSO provides with $T_{5 \%}$ values over $330-331^{\circ} \mathrm{C}$ with $1 \mathrm{wt} \%$ ECSO or MCSO while higher ECSO or
Table 2. Summary of the main results of the thermal degradation of neat PLA, PBAT and PLA/PBAT blend $(80 / 20 \mathrm{wt} / \mathrm{wt})$ without and with different compatibilizers.

\begin{tabular}{|l|c|c|}
\hline \multirow{2}{*}{\multicolumn{1}{c|}{ Code }} & \multicolumn{2}{c|}{ TGA } \\
\cline { 2 - 3 } & $\begin{array}{c}\boldsymbol{T}_{\mathbf{5} \%} \\
\left.{ }^{\circ} \mathbf{C}\right]\end{array}$ & $\begin{array}{c}\boldsymbol{T}_{\mathbf{5 0} \%} \\
{\left[{ }^{\circ} \mathbf{C}\right]}\end{array}$ \\
\hline PLA & 321.2 & 356.6 \\
\hline PBAT & 370.9 & 398.7 \\
\hline PLA/PBAT & 328.2 & 357.8 \\
\hline PLA/PBAT/1 ECSO & 331.7 & 359.8 \\
\hline PLA/PBAT/7.5 ECSO & 321.5 & 355.3 \\
\hline PLA/PBAT/1 MCSO & 330.5 & 358.3 \\
\hline PLA/PBAT/7.5 MCSO & 315.7 & 351.3 \\
\hline PLA/PBAT/1 Joncryl ${ }^{\circledR}$ & 305.9 & 344.1 \\
\hline
\end{tabular}

MCSO content leads to a small decrease in thermal stability, probably due to a plasticizer excess. This behavior has been reported previously with other vegetable oil-derived compatibilizers/plasticizers [49, 50]. Similar trend can be seen for $T_{50 \%}$. With regard to Joncryl ${ }^{\circledR}$, it leads to small decrease in thermal stability.

\subsection{Effect of compatibilizers on surface and disintegration properties of PLA/PBAT films}

The wetting properties of the herein developed materials was determined by contact angle measurements. Table 3 shows the water contact angle obtained on PLA, PBAT and their compatibilized and uncompatibilized blend. PLA shows an average contact angle of $66.4^{\circ}$ which is lower than typical polyolefins, i.e. poly(ethylene) - PE, poly(propylene) - PP, with contact angles close to $90^{\circ}[51,52]$. With regard to PBAT, due to its chemical structure, its water contact angle 
is located at $53.9^{\circ}$. Addition of all three compatibilizers at a fixed composition of $1 \mathrm{wt} \%$, provides increased hydrophobicity as the water contact angle increases up to values of about $71^{\circ}$ for Joncryl ${ }^{\circledR}$ and $75^{\circ}$ for ECSO and MCSO. Hydrophobicity is an interesting property in films so that, all three compatibilizers at $1 \mathrm{wt} \%$ give good results. Nevertheless, blends with $7.5 \mathrm{wt} \%$ of both ECSO and MCSO show a decrease in hydrophobicity (lower water contact angle values of about 63 and $56^{\circ}$ respectively). This could be related to phase separation at high vegetable oil content. Finely dispersed droplets of ECSO and MCSO could play an important role in reducing hydrophobicity due to their functionality [53]. Table 3 also summarizes the luminance $\left(L^{*}\right)$ which is a direct measurement of the transparency. Neat PLA film shows the highest transparency, with a $L^{*}$ of $99.4 \%$. All the developed formulations show high luminance, thus indicating very low effects on transparency. Disintegration in controlled compost soil gives interesting information about the effect of the different compatibilizers on the biodisintegration process. Figure 9 shows in a qualitative way the evolution of the disintegration process of neat PLA, PBAT and their uncompatibilized and compatibilized blend (1 wt $\%$ Joncryl ${ }^{\circledR}$, ECSO, MCSO). After an induction period of 11 days, relevant changes appear. Very smooth changes take place during this induction period. First changes are related to a change in PLA crystallinity due to hydrolysis as reported by $\mathrm{Xu}$ et $a l$. [54] The luminance is directly related to the transparency. Neat PLA film shows the highest transparency while the uncompatibilized PLA/PBAT shows decreased transparency (and decreased luminance as seen in Table 3). Both ECSO and MCSO contribute to slightly lower transparency and, consequently, the

Table 3. Summary of some surface properties, i.e. water contact angle and luminance $\left(L^{*}\right)$ for neat PLA, PBAT and PLA/PBAT blend (80/20 wt/wt) without and with different compatibilizers.

\begin{tabular}{|l|c|c|}
\hline \multicolumn{1}{|c|}{ Code } & $\begin{array}{c}\text { Water contact angle, } \boldsymbol{\theta}_{\mathbf{w}} \\
{\left[{ }^{\circ} \mathbf{l}\right.}\end{array}$ & $\begin{array}{c}\text { Luminance, } \\
\boldsymbol{L}^{*}\end{array}$ \\
\hline PLA & $66.4 \pm 1.6$ & $99.4 \pm 0.1$ \\
\hline PBAT & $53.9 \pm 1.1$ & $98.7 \pm 0.1$ \\
\hline PLA/PBAT & $66.2 \pm 3.4$ & $98.0 \pm 0.3$ \\
\hline PLA/PBAT/1 ECSO & $75.6 \pm 2.6$ & $98.1 \pm 0.1$ \\
\hline PLA/PBAT/7.5 ECSO & $62.7 \pm 1.4$ & $98.9 \pm 0.1$ \\
\hline PLA/PBAT/1 MCSO & $74.2 \pm 2.8$ & $98.3 \pm 0.2$ \\
\hline PLA/PBAT/7.5 MCSO & $56.3 \pm 4.0$ & $97.9 \pm 0.1$ \\
\hline PLA/PBAT/1 Joncryl ${ }^{\circledR}$ & $71.6 \pm 4.1$ & $99.1 \pm 0.1$ \\
\hline
\end{tabular}

change in luminance is very small. Although Joncryl compatibilized film could seem to be less transparent than ECSO and MCSO compatibilized blend films, it is important to remark that luminance values were obtained as average values of a series of measurements in different parts while images in Figure 9 are individual pictures.

It can be seen that PBAT delays the disintegration process since first signs of disintegration appears at 14 days whilst neat PLA is highly degraded at the same period. PBAT degradation rate is much higher than that of PLA. Tabasi et al. [55] reported an incubation time of 45 days on PBAT films which is noticeably higher than that of PLA. It is worthy to note that PLA is almost disintegrated at 16 days and all other formulations (uncompatibilized and compatibilized PLA/PBAT blends) degrade at 26 days. Although it has been reported that MCSO can lead to a reduction of the induction time in neat PLA [37], the herein developed blends show higher induction time due to presence of PBAT and a combination of different reactions with the compatibilizers, i.e. chain extension, branching and crosslinking, all those having an effect on delaying the disintegration time.

\section{Conclusions}

This work assesses the potential of vegetable oil-derived additives as compatibilizers in PLA/PBAT blends containing $20 \mathrm{wt} \%$ PBAT. The only addition of PBAT to PLA gives increased elongation at break due to the high flexibility of PBAT. Nevertheless, poor miscibility between PLA and PBAT was observed by FESEM and confirmed by a very low decrease in the glass transition temperature of neat PLA. Compatibilization with epoxidized cottonseed oil (ECSO) and maleinized cottonseed oil (MCSO), gave a remarkable increase in elongation at break without compromising other mechanical resistance properties. In fact, the compatibilized blend with $7.5 \mathrm{wt} \% \mathrm{MCSO}$ gives the best results in terms of balanced mechanical ductile and resistant properties, even better that those provided by an epoxy styrene-acrylic oligomer $\left(\right.$ Joncryl $l^{\circledR}$ ) widely used as chain extender and/or compatibilizer. The plasticization effect of the different compatibilizers is restricted as the glass transition temperature, $T_{\mathrm{g}}$, is not reduced in a great extent. Besides, the transparency of the films is not highly affected by the presence of the different additives. With regard to the disintegration process, PBAT delays the overall disintegration period due to its low 


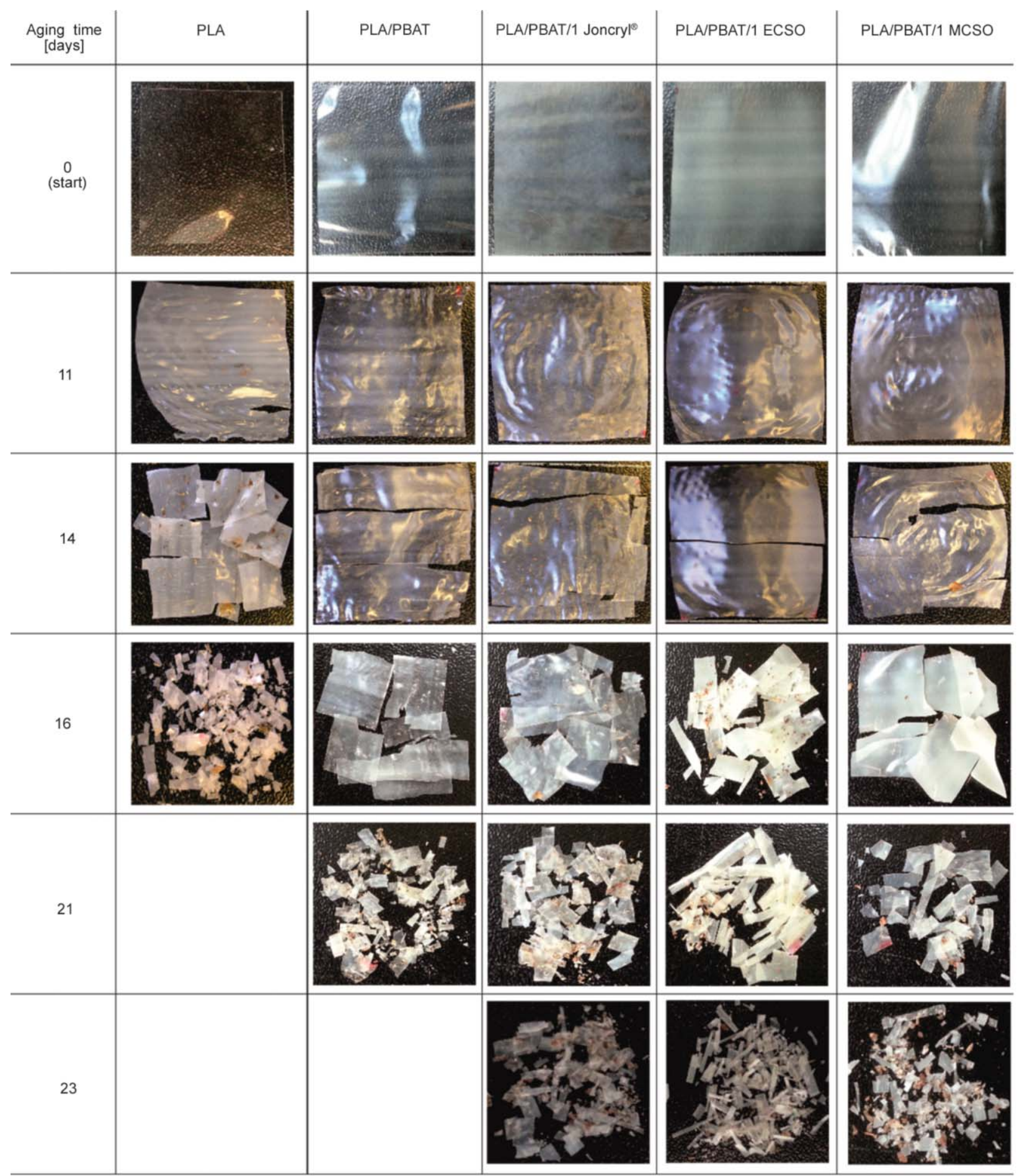

Figure 9. Qualitative assessment of the disintegration in controlled compost soil of neat PLA, PBAT and PLA/PBAT blend (80/20 wt/wt) without and with $1 \mathrm{wt} \%$ different compatibilizers.

disintegration rate. Both ECSO and MCSO do not have a relevant effect on overall disintegration but they contribute positively to improve the thermal stability as revealed by thermogravimetry. Use of vegetable oil-derived compatibilizers (epoxidized and maleinized vegetable oils) stands out as an environmentally friendly solution to improve miscibility of polyester-type blends with excellent balance on mechanical and thermal properties.

\section{Acknowledgements}

This work was supported by the Ministry of Economy and Competitiveness (MINECO) (grant number MAT201784909-C2-2-R). A. Carbonell-Verdu wants to thank Universitat Politècnica de València for financial support through an FPI grant. 


\section{References}

[1] Mirabal A. S., Scholz L., Carus M.: Market study and database on bio-based polymers in the world: Capacities, production and applications: Status quo and trends towards 2020. nova-Institut, Hürth (2013).

[2] Castro-Aguirre E., Iñiguez-Franco F., Samsudin H., Fang X., Auras R.: Poly(lactic acid) - Mass production, processing, industrial applications, and end of life. Advanced Drug Delivery Reviews, 107, 333-366 (2016). https://doi.org/10.1016/j.addr.2016.03.010

[3] Arrieta M. P., Fortunati E., Dominici F., Rayón E., López J., Kenny J. M.: PLA-PHB/cellulose based films: Mechanical, barrier and disintegration properties. Polymer Degradation and Stability, 107, 139-149 (2014). https://doi.org/10.1016/j.polymdegradstab.2014.05.010

[4] Yang W., Fortunati E., Dominici F., Giovanale G., Mazzaglia A., Balestra G. M., Kenny J. M., Puglia D.: Synergic effect of cellulose and lignin nanostructures in PLA based systems for food antibacterial packaging. European Polymer Journal, 79, 1-12 (2016). https://doi.org/10.1016/j.eurpolymj.2016.04.003

[5] Aydin E., Planell J. A., Hasirci V.: Hydroxyapatite nanorod-reinforced biodegradable poly(L-lactic acid) composites for bone plate applications. Journal of Materials Science: Materials in Medicine, 22, 2413-2427 (2011). https://doi.org/10.1007/s10856-011-4435-z

[6] Baig G. A., Carr C. M.: Surface and structural damage to PLA fibres during textile pretreatments. Fibres and Textiles in Eastern Europe, 24, 52-58 (2016). https://doi.org/10.5604/12303666.1191427

[7] Samper M. D., Fages E., Fenollar O., Boronat T., Balart R.: The potential of flavonoids as natural antioxidants and uv light stabilizers for polypropylene. Journal of Applied Polymer Science, 129, 1707-1716 (2013). https://doi.org/10.1002/app.38871

[8] Fenollar O., Garcia-Sanoguera D., Sanchez-Nacher L., Lopez J., Balart R.: Effect of the epoxidized linseed oil concentration as natural plasticizer in vinyl plastisols. Journal of Materials Science, 45, 4406-4413 (2010). https://doi.org/10.1007/s10853-010-4520-6

[9] Ferri J. M., Samper M. D., Garcia-Sanoguera D., Reig M. J., Fenollar O., Balart R.: Plasticizing effect of biobased epoxidized fatty acid esters on mechanical and thermal properties of poly(lactic acid). Journal of Materials Science, 51, 5356-5366 (2016). https://doi.org/10.1007/s10853-016-9838-2

[10] Fombuena V., Sanchez-Nácher L., Samper M. D., Juárez D., Balart R.: Study of the properties of thermoset materials derived from epoxidized soybean oil and protein fillers. Journal of the American Oil Chemists' Society, 90, 449-457 (2013). https://doi.org/10.1007/s11746-012-2171-2

[11] Xu H., Adolfsson K. H., Xie L., Hassanzadeh S., Pettersson T., Hakkarainen M.: Zero-dimensional and highly oxygenated graphene oxide for multifunctional poly(lactic acid) bionanocomposites. ACS Sustainable Chemistry and Engineering, 4, 5618-5631 (2016). https://doi.org/10.1021/acssuschemeng.6b01524
[12] Xu H., Bai Y., Xie L., Li J., Hakkarainen M.: Heat-resistant and microwaveable poly(lactic acid) by quantum-dot-promoted stereocomplexation. ACS Sustainable Chemistry and Engineering, 5, 11607-11617 (2017). https://doi.org/10.1021/acssuschemeng.7b02963

[13] Xu H., Xie L., Li J., Hakkarainen M.: Coffee grounds to multifunctional quantum dots: Extreme nanoenhancers of polymer biocomposites. ACS Applied Materials and Interfaces, 9, 27972-27983 (2017). https://doi.org/10.1021/acsami.7b09401

[14] Xu H., Zhong G-J., Fu Q., Lei J., Jiang W., Hsiao B. S., Li Z-M.: Formation of shish-kebabs in injection-molded poly(L-lactic acid) by application of an intense flow field. ACS Applied Materials and Interfaces, 4, 67736783 (2012). https://doi.org/10.1021/am3019756

[15] Lim L-T., Auras R., Rubino M.: Processing technologies for poly(lactic acid). Progress in Polymer Science, 33, 820-852 (2008).

https://doi.org/10.1016/j.progpolymsci.2008.05.004

[16] Ferri J. M., Fenollar O., Jorda-Vilaplana A., GarcíaSanoguera D., Balart R.: Effect of miscibility on mechanical and thermal properties of poly(lactic acid)/polycaprolactone blends. Polymer International, 65, 453463 (2016). https://doi.org/10.1002/pi.5079

[17] de M. Teixeira E., Curvelo A. A. S., Corrêa A. C., Marconcini J. M., Glenn G. M., Mattoso L. H. C.: Properties of thermoplastic starch from cassava bagasse and cassava starch and their blends with poly (lactic acid). Industrial Crops and Products, 37, 61-68 (2012).

https://doi.org/10.1016/j.indcrop.2011.11.036

[18] Yokohara T., Yamaguchi M.: Structure and properties for biomass-based polyester blends of PLA and PBS. European Polymer Journal, 44, 677-685 (2008). https://doi.org/10.1016/j.eurpolymj.2008.01.008

[19] Jiang L., Wolcott M. P., Zhang J. W.: Study of biodegradable polylactide/poly(butylene adipate-co-terephthalate) blends. Biomacromolecules, 7, 199-207 (2006). https://doi.org/10.1021/bm050581q

[20] Takayama T., Daigaku Y., Ito H., Takamori H.: Mechanical properties of bio-absorbable PLA/PGA fiber-reinforced composites. Journal of Mechanical Science and Technology, 28, 4151-4154 (2014). https://doi.org/10.1007/s12206-014-0927-3

[21] Arrieta M. P., Samper M. D., López J., Jiménez A.: Combined effect of poly(hydroxybutyrate) and plasticizers on polylactic acid properties for film intended for food packaging. Journal of Polymers and the Environment, 22, 460-470 (2014). https://doi.org/10.1007/s10924-014-0654-y

[22] Muniyasamy S., Ofosu O., John M. J., Anandjiwala R. D.: Mineralization of poly(lactic acid) (PLA), poly(3hydroxybutyrate-co-valerate) (PHBV) and PLA/PHBV blend in compost and soil environments. Journal of Renewable Materials, 4, 133-145 (2016). https://doi.org/10.7569/JRM.2016.634104 
[23] Quero E., Müller A. J., Signori F., Coltelli M-B., Bronco S.: Isothermal cold-crystallization of PLA/PBAT blends with and without the addition of acetyl tributyl citrate. Macromolecular Chemistry and Physics, 213, 36-48 (2012).

https://doi.org/10.1002/macp.201100437

[24] Mittal V., Akhtar T., Matsko N.: Mechanical, thermal, rheological and morphological properties of binary and ternary blends of PLA, TPS and PCL. Macromolecular Materials and Engineering, 300, 423-435 (2015). https://doi.org/10.1002/mame.201400332

[25] Garcia-Campo M. J., Quiles-Carrillo L., Masia J., ReigPérez M. J., Montanes N., Balart R.: Environmentally friendly compatibilizers from soybean oil for ternary blends of poly(lactic acid)-PLA, poly(epsilon-caprolactone)-PCL and poly(3-hydroxybutyrate)-PHB. Materials, 10, 1339/1-1339/19 (2017).

https://oi.org/10.3390/ma10111339

[26] Kfoury G., Hassouna F., Raquez J-M., Toniazzo V., Ruch D., Dubois P.: Tunable and durable toughening of polylactide materials via reactive extrusion. Macromolecular Materials and Engineering, 299, 583-595 (2014). https://doi.org/10.1002/mame.201300265

[27] Yuryev Y., Mohanty A. K., Misra M.: A new approach to supertough poly(lactic acid): A high temperature reactive blending. Macromolecular Materials and Engineering, 301, 1443-1453 (2016).

https://doi.org/10.1002/mame.201600242

[28] Ojijo V., Sinha Ray S., Sadiku R.: Toughening of biodegradable polylactide/poly(butylene succinate-co-adipate) blends via in situ reactive compatibilization. ACS Applied Materials and Interfaces, 5, 4266-4276 (2013). https://doi.org/10.1021/am400482f

[29] Al-Itry R., Lamnawar K., Maazouz A.: Rheological, morphological, and interfacial properties of compatibilized PLA/PBAT blends. Rheologica Acta, 53, 501-517 (2014).

https://doi.org/10.1007/s00397-014-0774-2

[30] Torres-Giner S., Montanes N., Boronat T., Quiles-Carrillo L., Balart R.: Melt grafting of sepiolite nanoclay onto poly(3-hydroxybutyrate-co-4-hydroxybutyrate) by reactive extrusion with multi-functional epoxy-based styrene-acrylic oligomer. European Polymer Journal, 84, 693-707 (2016).

https://doi.org/10.1016/j.eurpolymj.2016.09.057

[31] Bureepukdee C., Suttiruengwong S., Seadan M.: A study on reactive blending of (poly lactic acid) and poly(butylene succinate co adipate). IOP Conference Series: Materials Science and Engineering, 87, 012070/1-012070/7 (2015). https://doi.org/10.1088/1757-899X/87/1/012070

[32] Lligadas G., Ronda J. C., Galià M., Cádiz V.: Renewable polymeric materials from vegetable oils: A perspective. Materials Today, 16, 337-343 (2013). https://doi.org/10.1016/j.mattod.2013.08.016
[33] Carbonell-Verdu A., Garcia-Sanoguera D., Jordá-Vilaplana A., Sanchez-Nacher L., Balart R.: A new biobased plasticizer for poly(vinyl chloride) based on epoxidized cottonseed oil. Journal of Applied Polymer Science, 133, 43642/1-43642/10 (2016). https://doi.org/10.1002/app.43642

[34] España J. M., Samper M. D., Fages E., Sánchez-Nácher L., Balart R.: Investigation of the effect of different silane coupling agents on mechanical performance of basalt fiber composite laminates with biobased epoxy matrices. Polymer Composites, 34, 376-381 (2013). https://doi.org/10.1002/pc.22421

[35] Carbonell-Verdu A., Samper M. D., Garcia-Garcia D., Sanchez-Nacher L., Balart R.: Plasticization effect of epoxidized cottonseed oil (ECSO) on poly(lactic acid). Industrial Crops and Products, 104, 278-286 (2017). https://doi.org/10.1016/j.indcrop.2017.04.050

[36] Garrison T. F., Zhang Z. Y., Kim H-J., Mitra D., Xia Y., Pfister D. P., Brehm-Stecher B. F., Larock R. C., Kessler M. R.: Thermo-mechanical and antibacterial properties of soybean oil-based cationic polyurethane coatings: Effects of amine ratio and degree of crosslinking. Macromolecular Materials and Engineering, 299, 1042-1051 (2014).

https://doi.org/10.1002/mame.201300423

[37] Carbonell-Verdu A., Garcia-Garcia D., Dominici F., Torre L., Sanchez-Nacher L., Balart R.: PLA films with improved flexibility properties by using maleinized cottonseed oil. European Polymer Journal, 91, 248-259 (2017).

https://doi.org/10.1016/j.eurpolymj.2017.04.013

[38] Ferri J. M., Garcia-Garcia D., Montanes N., Fenollar O., Balart R.: The effect of maleinized linseed oil as biobased plasticizer in poly(lactic acid)-based formulations. Polymer International, 66, 882-891 (2017). https://doi.org/10.1002/pi.5329

[39] Ferri J. M., Garcia-Garcia D., Sánchez-Nacher L., Fenollar O., Balart R.: The effect of maleinized linseed oil (MLO) on mechanical performance of poly(lactic acid)thermoplastic starch (PLA-TPS) blends. Carbohydrate Polymers, 147, 60-68 (2016).

https://doi.org/10.1016/j.carbpol.2016.03.082

[40] Carbonell-Verdu A., Bernardi L., Garcia-Garcia D., Sanchez-Nacher L., Balart R.: Development of environmentally friendly composite matrices from epoxidized cottonseed oil. European Polymer Journal, 63, 110 (2015).

https://doi.org/10.1016/j.eurpolymj.2014.11.043

[41] Quiles-Carrillo L., Blanes-Martínez M. M., Montanes N., Fenollar O., Torres-Giner S., Balart R.: Reactive toughening of injection-molded polylactide pieces using maleinized hemp seed oil. European Polymer Journal, 98, 402-410 (2018).

https://doi.org/10.1016/j.eurpolymj.2017.11.039 
[42] Quiles-Carrillo L., Duart S., Montanes N., Torres-Giner S., Balart R.: Enhancement of the mechanical and thermal properties of injection-molded polylactide parts by the addition of acrylated epoxidized soybean oil. Materials and Design, 140, 54-63 (2018).

https://doi.org/10.1016/j.matdes.2017.11.031

[43] Quiles-Carrillo L., Montanes N., Sammon C., Balart R., Torres-Giner S.: Compatibilization of highly sustainable polylactide/almond shell flour composites by reactive extrusion with maleinized linseed oil. Industrial Crops and Products, 111, 878-888 (2018). https://doi.org/10.1016/j.indcrop.2017.10.062

[44] Dil E. J., Carreau P. J., Favis B. D.: Morphology, miscibility and continuity development in poly(lactic acid)/ poly(butylene adipate-co-terephthalate) blends. Polymer, 68, 202-212 (2015).

https://doi.org/10.1016/j.polymer.2015.05.012

[45] Garcia-Garcia D., Fenollar O., Fombuena V., LopezMartinez J., Balart R.: Improvement of mechanical ductile properties of poly(3-hydroxybutyrate) by using vegetable oil derivatives. Macromolecular Materials and Engineering, 302, 1600330/1-1600330/12 (2017).

https://doi.org/10.1002/mame.201600330

[46] Abdelwahab M. A., Taylor S., Misra M., Mohanty A. K.: Thermo-mechanical characterization of bioblends from polylactide and poly(butylene adipate-co-terephthalate) and lignin. Macromolecular Materials and Engineering, 300, 299-311 (2015).

https://doi.org/10.1002/mame.201400241

[47] Al-Itry R., Lamnawar K., Maazouz A., Billon N., Combeaud C.: Effect of the simultaneous biaxial stretching on the structural and mechanical properties of PLA, pbat and their blends at rubbery state. European Polymer Journal, 68, 288-301 (2015).

https://doi.org/10.1016/j.eurpolymj.2015.05.001

[48] Lu X., Zhao J., Yang X., Xiao P.: Morphology and properties of biodegradable poly (lactic acid)/poly (butylene adipate-co-terephthalate) blends with different viscosity ratio. Polymer Testing, 60, 58-67 (2017). https://doi.org/10.1016/j.polymertesting.2017.03.008
[49] Garcia-Garcia D., Ferri J. M., Montanes N., LopezMartinez J., Balart R.: Plasticization effects of epoxidized vegetable oils on mechanical properties of poly(3hydroxybutyrate). Polymer International, 65, 11571164 (2016). https://doi.org/10.1002/pi.5164

[50] Balart J. F., Fombuena V., Fenollar O., Boronat T., Sánchez-Nacher L.: Processing and characterization of high environmental efficiency composites based on PLA and hazelnut shell flour (HSF) with biobased plasticizers derived from epoxidized linseed oil (ELO). Composites Part B: Engineering, 86, 168-177 (2016). https://doi.org/10.1016/j.compositesb.2015.09.063

[51] Fombuena V., Balart J., Boronat T., Sánchez-Nácher L., Garcia-Sanoguera D.: Improving mechanical performance of thermoplastic adhesion joints by atmospheric plasma. Materials and Design, 47, 49-56 (2013). https://doi.org/10.1016/j.matdes.2012.11.031

[52] Pandiyaraj K. N., Deshmukh R. R., Arunkumar A., Ramkumar M. C., Ruzybayev I., Shah S. I., Su P-G., Periayah M. H., Halim A. S.: Evaluation of mechanism of non-thermal plasma effect on the surface of polypropylene films for enhancement of adhesive and hemo compatible properties. Applied Surface Science, 347, 336-346 (2015). https://doi.org/10.1016/j.apsusc.2015.04.097

[53] Zolali A. M., Favis B. D.: Partial to complete wetting transitions in immiscible ternary blends with PLA: The influence of interfacial confinement. Soft Matter, 13, 2844-2856 (2017).

https://doi.org/10.1039/c6sm02386j

[54] Xu H., Yang X., Xie L., Hakkarainen M.: Conformational footprint in hydrolysis-induced nanofibrillation and crystallization of poly(lactic acid). Biomacromolecules, 17, 985-995 (2016).

https://doi.org/10.1021/acs.biomac.5b01636

[55] Tabasi R. Y., Ajji A.: Selective degradation of biodegradable blends in simulated laboratory composting. Polymer Degradation and Stability, 120, 435-442 (2015). https://doi.org/10.1016/j.polymdegradstab.2015.07.020 